\title{
Genetic risk factors of chronic venous leg ulceration: Can molecular screening aid in the prevention of chronic venous insufficiency complications?
}

\author{
TOMASZ GRZELA and AGATA BIALOSZEWSKA \\ Cell Molecular Biology Laboratory, Department of Histology and Embryology, \\ Warsaw Medical University, PL 02-004 Warsaw, Poland
}

Received December 1, 2009; Accepted January 27, 2010

DOI: $10.3892 / \mathrm{mmr} 00000241$

\begin{abstract}
Venous leg ulceration is a severe complication of chronic venous insufficiency. Despite numerous studies, understanding of the possible mechanisms involved in venous ulceration development remains incomplete. It is assumed that, in addition to well-documented behavioral and/or environmental conditions, as yet poorly defined genetic risk factors may play important roles in chronic wound progression or healing. It is difficult to overestimate the clinical usefulness of genetic screening in the determination of the risk of wound development and/or its healing course. From a pharmacogenomic perspective, genetic screening may aid in the planning of individualized treatment. In addition, the detection of venous ulcer-promoting gene variants may facilitate the decision to introduce prophylaxis or, if necessary, appropriate treatment for venous insufficiency, long before a leg ulcer develops. In addition to significant economic benefits, this approach would reduce the risk of health- and life-threatening conditions. In this review, we focus on several gene mutations/polymorphisms with previously documented significance in leg ulceration pathophysiology, and briefly speculate about possible candidates for further study.
\end{abstract}

\section{Contents}

1. Introduction

2. Inherited thrombophilia

3. Factor V Leiden polymorphism

4. Prothrombin G20210A variant

5. Methylenetetrahydrofolate reductase polymorphism

Correspondence to: Dr Tomasz Grzela, Cell Molecular Biology Laboratory, Department of Histology and Embryology, Warsaw Medical University, Chalubinskiego 5, PL 02-004 Warsaw, Poland E-mail: tgrzela@op.pl; tgrzela@ib.amwaw.edu.pl

Key words: gene polymorphism, venous leg ulcer, wound healing
6. Other chronic venous ulceration development-promoting gene mutations/single nucleotide polymorphisms

7. Chronic venous ulceration healing-promoting variants

8. Conclusions

\section{Introduction}

Chronic venous ulceration (CVU) of the lower extremities develops as a severe and burdensome complication of chronic venous insufficiency (CVI). The frequency of CVU in the entire human population does not exceed $0.5-1 \%$; however, it increases significantly in older patients, reaching $5 \%$ in individuals above the age of 65 years $(1,2)$. According to statistical data, there are approximately 0.5 million individuals suffering from CVU in the US. Among these, CVU-related work absence in employed patients is estimated to amount to 6 million working days per year. Thus, in addition to other costs, the annual budget cost of CVU reaches 1.9-2.5 billion US dollars (3).

Due to pain, odorous exudate and an extremely long healing process, chronic leg ulceration impairs the professional and social life of a patient, and its effect on the psyche and selfesteem significantly decreases quality of life (4). Thus, CVU is becoming recognized as a significant public health problem, with serious social and economic consequences.

Despite numerous studies, the current understanding of the possible mechanisms of CVU development and healing remains incomplete. Although CVU patients display similar clinical features (comparable stage of venous insufficiency and similar concomitant conditions/diseases), they may differ significantly in predisposition to CVU formation, as well as in healing time (5-7). There have been reports indicating that the observed differences between patients may result from variations at the molecular level $(8,9)$. Recent progress in genetic research, mainly the achievements of the Human Genome Project, has encouraged scientists to review the influence of a patient's genetic profile on chronic wound progression or regeneration. An especially promising approach seems to be the analysis of possible mutations or single nucleotide polymorphisms (SNP) of particular genes engaged in angiogenesis, growth and differentiation, cellular stress control, cell 
proliferation, and apoptosis. In this review, we focus on several gene mutations/polymorphisms with previously documented significance in CVU pathophysiology. Furthermore, we briefly speculate about possible candidates for further study.

\section{Inherited thrombophilia}

Deep venous thrombosis (DVT), although not involved directly in CVU formation, has been recognized as an important risk factor associated with its development (10). It is clear that DVT may result from inherited or acquired abnormalities of the coagulation system, known as thrombophilias. According to a recent study by Darvall et al (11), 75\% of CVU-suffering patients display single or multiple thrombophilias that predispose them to an increased occurrence of clinical and subclinical thrombosis. Indeed, approximately $43 \%$ of CVU individuals have had at least one previous clinically overt DVT episode. However, many patients have no clear history of DVT or ultrasound duplex-doppler evidence of previous thrombosis (10). In addition to the well-defined importance of post-thrombotic insufficiency in larger deep vein trunks, there is increasing evidence of the key role of microvascular thrombosis in CVU development. These changes, together with fibrin cuff, leukocyte infiltration and overexpression of pro-inflammatory cytokines and adhesion molecules, may contribute to a significant impairment of tissue perfusion and oxygenation (11-13). The stress response to ischemia/reperfusion may result in tissue injury, further increasing the risk of chronic ulcer formation.

The prevalence of no, single or multiple thrombophiliaassociated gene variants in CVU individuals has been reported as 26,30 and $44 \%$, respectively (11). When compared to age- and gender-matched control subjects, this prevalence is increased by 3 - to 4 -fold, reaching as high as 66,22 and $11 \%$, respectively. As expected, the most common DVT-associated inherited thrombophilic abnormalities (factor $\mathrm{V}$ Leiden, prothrombin G20210A variant and MTHFR C677T SNP) were found at a higher frequency in CVU patients $(10,11,14)$.

\section{Factor V Leiden polymorphism}

Factor V Leiden is an autosomal dominant (with incomplete dominance) single nucleotide substitution located in exon 10 of the factor $\mathrm{V}$ gene (15). Normally, factor $\mathrm{V}$ is a cofactor for the activation of thrombin by coagulation factor $\mathrm{X}$. Thrombin is an enzyme responsible for the cleavage of fibrinogen to fibrin, followed by fibrin polymerization and clot formation. This reaction is controlled by a natural anticoagulant, activated protein $\mathrm{C}$ (aPC), which is responsible for factor $\mathrm{V}$ degradation. The G1691A substitution incorporates glutamine instead of arginine at amino acid residue 506 (R506Q) of factor V. Since the 506 amino acid position constitutes the cleavage site for aPC, this substitution makes factor $\mathrm{V}$ protein more resistant to inactivation by aPC. Thus, it facilitates thrombin overproduction with excessive generation of fibrin, and finally leads to a hypercoagulable state (16).

Although the mutant allele is found at a frequency of approximately 5\% in Caucasian populations, the prevalence of this SNP in patients with recognized venous thrombosis is as high as $30 \%$ (11), whereas in the group of CVU-suffering individuals it ranges between 8 and 36\%, depending on the estimated population size $(11,17)$. Heterozygotes present a 8 -fold increased risk of DVT. However, homozygous patients (approximately $1 \%$ of patients with the factor $\mathrm{V}$ Leiden variant) display a 100-fold higher risk of developing DVT and present a more severe clinical condition than those carrying the wild-type factor $\mathrm{V}$ gene (17-19).

\section{Prothrombin G20210A variant}

An independent risk factor for venous thrombosis and, presumably, for CVU development, is a common genetic variation in the 3'-untranslated region (UTR) of the prothrombin gene, located on chromosome $11(20,21)$.

Under physiological conditions, the gene product prothrombin is enzymatically cleaved to its active form, thrombin (factor II), by activated factor $X$. Subsequently, thrombin, due to its serine protease activity, converts soluble fibrinogen molecules into fibrin, which precipitate to form a fibrin clot.

A $\mathrm{G} \rightarrow \mathrm{A}$ substitution at the 20210 nucleotide position is associated with an increased synthesis and higher level of prothrombin in plasma (22-24). The morbidity rate in heterozygous carriers of the 20210A variant is 3- to 5-fold higher than in wild-type individuals $(10,11)$. While, in the general population, the prothrombin 20210A variant is found in $2 \%$ of individuals, approximately $6 \%$ of patients with venous thrombosis and up to $4 \%$ of individuals with $\mathrm{CVU}$ are positive for this substitution (22-24).

\section{Methylenetetrahydrofolate reductase polymorphism}

Recent studies provide increasing evidence for the importance of hyperhomocysteinemia (HHcy) as a risk factor in DVT and/ or CVU development $(10,11,25)$. It has been demonstrated that a moderate HHcy, defined as a homocysteine (Hcy) plasma concentration above $16.6 \mu \mathrm{M}$, results in a 2- to 3-fold higher DVT risk, as compared to individuals with Hcy levels below that value (11). Furthermore, a moderate HHcy is correlated with a 5-fold increased risk of CVU development. HHcy is found in $5 \%$ of individuals in the general population, while its prevalence in CVU-suffering individuals is as high as $40.7 \%$ (25-27).

The most common genetic abnormality associated with HHcy has been found in a gene encoding for methylenetetrahydrofolate reductase (MTHFR), an enzyme responsible for Hcy metabolism (28). This C677T substitution leads to a change of alanine to valine and, as has been demonstrated in vitro $(28,29)$, produces the MTHFR gene product thermolabile, resulting in a $70 \%$ reduction of the enzymatic activity of the gene. Heterozygous occurrence of the $677 \mathrm{~T}$ variant is very common (as high as 50\% of screened individuals), but does not necessarily lead to hyperhomocysteinemia (30). Notably, also in homozygous individuals (as high as 15\% of screened patients), the normal Hcy level may be maintained by a sufficient folate supply. However, in the same patients, the Hcy level increases significantly in the presence of vitamin B6, $\mathrm{B} 12$, or folate deficiencies $(29,31)$.

It remains unclear whether the MTHFR C677T SNP is associated with an increased risk of DVT/CVU, since various studies confirm this relationship while others have shown weak positive associations $(11,26,28,29,32,33)$. Moreover, it is difficult to assess whether the presence of the inherited throm- 
bophilic polymorphisms mentioned above truly correlates with an increased susceptibility to CVU. There are significant discrepancies in the reported frequency of all of the described genetic variants and their presumable role in CVU development (11). This may be due to the relatively small number of cases in cited studies. Thus, one can argue that the correlation of thrombophilic SNPs with CVU formation is actually secondary to DVT episodes (34). However, it may be difficult to elucidate this issue, as it will require further studies using large populations of CVU patients with no history of thrombosis.

\section{Other chronic venous ulceration development-promoting gene mutations/single nucleotide polymorphisms}

Recently, in addition to hereditary thrombophilia, other genetically determined CVU-predisposing conditions have been described. Several of the more extensively studied mutations and SNPs concern genes encoding for pro-inflammatory or angiogenesis-regulating factors and their receptors.

TNF gene variants. It has been demonstrated that, in chronic venous leg ulcer-derived wound fluid, levels of interleukin-1 (IL-1), tumour necrosis factor (TNF), and matrix metalloproteinase (MMP)-2, -3 and -9 are higher in comparison to those in normal acute wounds (35-39). Various polymorphisms in genes encoding these molecules have been investigated by numerous research groups. Wallace et al found one SNP that may be an important risk factor for venous ulceration: the $-308 \mathrm{G} / \mathrm{A}$ variant, located in the promoter of the TNFA gene (40). Individuals with the TNFA -308A allele display an approximately 2 -fold higher risk of ulceration than wildtype carriers. Although data indicate that the $-308 \mathrm{G} / \mathrm{A}$ polymorphism results in an increased level of gene product (41), the role of this particular SNP in leg ulcer development is in need of further precise investigation. A significant obstacle to data interpretation is the location of the TNFA gene. It is located in the central region of the major histocompatibility complex (MHC), which results in the subsequent occurrence of the 8.1 ancestral haplotype in $70 \%$ of Caucasians with TNFA -308A. This haplotype is associated with a variety of immunological disorders, and may therefore also affect leg ulcer formation $(40,41)$.

The TNFA -308A allele has also been linked to obesity and insulin resistance $(42,43)$. However, Nagy et al found no difference in the frequency of the A allele between non-obese venous leg ulcer patients and non-obese healthy controls. On the other hand, a significant difference in the presence of the TNFA -308A SNP was found between obese CVU individuals and non-obese healthy controls (44). These results suggest that the described TNFA SNP is not a primary risk factor for CVU.

FGF-R SNP. Successful wound healing requires proper control of connective tissue regeneration. The key element of this controlling system is the large family of cytokines: fibroblast growth factors (FGFs) and their receptors (FGF-Rs) (45). Any disturbances in this controlling system have the potential to cause a delay in wound healing.

Nagy et al found that the occurrence of various SNPs in the 3'-UTR of the gene encoding for fibroblast growth factorreceptor type 2 (FGF-R2) was statistically more frequent in individuals suffering from chronic venous ulceration than in healthy controls (46). Among the various polymorphisms studied to date, the most frequently recognized SNP in this region is A2451G. It has been found that impaired regeneration of connective tissue and longer re-epithelialization in CVU could, at least in part, be explained by lower expression of FGF-R2, resulting from the above-mentioned SNPs. However, it is unclear whether decreased protein levels result from suppressed gene expression or are a consequence of the altered stability of primary mRNA (46). Moreover, it is noteworthy that the same SNPs have been linked to the development of venous insufficiency. This observation indicates the need to verify whether these FGF-R2 variants are directly involved in venous ulcer formation and/or impaired healing, or whether, due to CVI development, they are secondary risk factors of CVU.

It is plausible that other known FGF-R2 SNPs, not yet analyzed in the context of their association with CVU, may be of interest for further study. It has been shown that the majority of FGF-R2 gene mutations leading to a predisposition to breast cancer development are located in the intronic parts of the gene (47-49). Although there have been reports suggesting that intronic SNPs play a role in the regulation of gene expression and its alternative splicing, their significance in FGF-R2 gene function remains unclear. It has been demonstrated that an alternative splicing of FGF-R2 mRNA may result in the generation of two molecules involved in wound healing, keratinocyte growth factor receptor (KGFR) and bacterially expressed kinase (BEK), thus modulating the reactivity of wound bed cells to various cytokines from the FGF family $(45,50)$.

Estrogen receptor $S N P$. An important observation regarding genetically determined susceptibility to CVU concerns the possible role of steroid hormone receptors, mainly the receptor for estrogen (ER) (51,52). Estrogen is known to improve the condition of the skin by supporting extracellular matrix metabolism (53). It has been demonstrated that hormone replacement therapy (HRT) in post-menopausal women prevents the formation of CVU (54). Moreover, topical estrogen treatment significantly reduces inflammatory reaction at the wound site, improving ulcer healing in elderly patients (55).

Estrogen-induced signal transduction engages two estrogen receptor proteins, ER $\alpha$ and $\beta$. Although several SNPs have been found in genes encoding for both ERs, only those located in the region encoding for $\mathrm{ER} \beta$ have been shown to predispose elderly individuals to CVU development $(51,52)$. However, the precise determination of the relationship between particular ER $\beta$ SNPs and CVU susceptibility is required.

HFE polymorphism. Hemochromatosis $(\mathrm{HH})$ is an inherited disease that results from mutations or polymorphisms of the gene encoding for a MHC class I-type membrane protein, which is associated with $\beta 2$-microglobulin. It is thought that the main function of the protein is the regulation of iron absorption through the control of the interaction between the transferrin receptor and transferrin (56). HH prevalence in individuals of northern European descent is approximately $0.5 \%$; however, approximately $10 \%$ of individuals in this demographic group carry a mutation in one of the $\mathrm{HH}$-associated 
genes: the HFE gene, with the two most common HFE alleles C282Y and H63D (57).

The first polymorphism, a $\mathrm{G} \rightarrow \mathrm{A}$ substitution, results in a cysteine to tyrosine exchange in codon 282 (C282Y). The second SNP is a histidine to asparaginic acid substitution in codon 63 (H63D). When homozygous, 282Y is considered to be the most common genotype responsible for clinically overt symptoms of iron accumulation. Although an occurrence of both HFE variants in the Caucasian population is relatively high, reaching $9.2 \%$ for $282 \mathrm{Y}$ and $22 \%$ for $63 \mathrm{D}$, their penetration is usually insufficient to affect the heterozygous patient state (57-60). However, heterozygosity for 282Y/63D variants, so-called compound heterozygotes, results in a clinically evident iron overload and associated conditions, with a greatly increased risk of lesion development (61).

In CVI-suffering patients, venous blood stasis and hypertension in the venous circulation of the lower extremities may result in easy red blood cell extravasations and their haemolysis. This leads to iron-containing haemoglobin derivative deposition in the tissues surrounding blood vessels. The impaired transport of iron by macrophages results in an accumulation of reactive ferric ions in affected tissues, and leads to increased free radical generation. These events increase oxidative stress, augment the inflammatory response and facilitate further tissue destruction (57,61-63). Thus, they enhance the risk of primary ulcer formation, and impair wound healing. It has been demonstrated that, in CVU individuals, the $282 \mathrm{Y}$ variant increases the risk of ulcer formation in patients with primary CVI by almost 7-fold, whereas the presence of the $63 \mathrm{D}$ allele is responsible for significantly lower age (up to 10 years) of ulcer onset $(61,63,64)$.

Based on this observation, Zamboni and Gemmati proposed HFE SNP screening for chronic venous insufficiency patients as an ulcer prevention method (61). Although in some cases it is impossible to prevent ulcer development, the screening would nevertheless presumably allow for the prediction of the potential of wound progression.

VEGF polymorphism. Successful wound healing depends on effective angiogenesis, which comprises the formation of new blood vessels in granular tissue (65). The most potent mitogen for endothelial cells is vascular endothelial growth factor (VEGF), which plays a key role in the regulation of angiogenesis. Impaired angiogenesis resulting from genetically determined abnormalities in the VEGF expression level or cytokine structure itself has been observed in various pathologies (66). Therefore, the highly polymorphic VEGF gene has been the subject of numerous studies concerning the role of VEGF gene variants in diabetes complications, rheumatoid arthritis, renal allograft rejection, psoriasis, endometriosis, gastroduodenal ulcers and various cancers (67-69). Among various polymorphisms in the VEGF gene studied to date, two were found to be significantly associated with impaired expression of this cytokine, and thus could be considered potent risk factors of impaired chronic wound healing. It has been demonstrated that the C936T SNP in the 3'-UTR of the VEGF gene is associated with a reduced serum level of cytokine $(69,70)$. More recently, a novel SNP in the VEGF promoter $(-1780 \mathrm{~T} / \mathrm{C})$, which was found to significantly affect gene expression, has been described (67). The authors reported a strong relationship between this SNP and the occurrence of gastroduodenal ulcers. Moreover, they confirmed that the transfection of the HMEC-1 endothelial cell line with the $-1780 \mathrm{~T} / \mathrm{C}$ SNP-containing vector influenced the angiogenic activity of these cells in vitro. Indeed, cells transfected with this mutant vector displayed repressed promoter activity as compared to cells transfected with the wild-type vector, and subsequently displayed impaired angiogenic potential (67).

Despite numerous studies on the possible clinical implications of other VEGF SNPs, there is no consensus regarding their relationship to various diseases (71). The main difficulty in the analysis of the data is a discrepancy among the various reports, possibly due to the significant diversity of the studied populations. Thus, further verification is required.

\section{CVU healing-promoting variants}

FXIII subunit A polymorphism. In contrast to the previously described CVU formation-inducing polymorphisms, variants of certain genes also facilitate wound healing. Among these is a polymorphism concerned with a gene encoding for coagulation factor XIII (FXIII) subunit A (72-74).

Factor XIII is a tetramer composed of two catalytic A- and two accessory B-subunits. After activation by thrombin, factor XIII catalyzes covalent crosslinking of the fibrin net, thus improving its mechanical strength and resistance to fibrinolysis (75,76). In addition to its main physiological function, FXIII is capable of crosslinking other extracellular matrix components, including fibronectin, collagens and laminin. These modifications increase fibroblast proliferation and migration potential, modulate the effects of MMP activity and enhance angiogenesis (77-79), thus indicating the pivotal role of FXIII in ulcer healing. In fact, it has been demonstrated that, in patients with CVU displaying low levels of endogenous FXIII, a local application of exogenous FXIII stimulated lesion regression (80).

Of note, detailed studies of FXIII gene polymorphisms have demonstrated that the $\mathrm{G} \rightarrow \mathrm{T}$ transversion common in Caucasians, which occurs in codon 34 and results in valine changing into leucin, leads to an increase in FXIII activity. Since the amino acid substitution occurs near the catalytic region, it may enhance specific substrate binding (81-83). It has been proposed that the FXIII-A 34L variant displays improved crosslinking activity towards extracellular matrix components, thus further augmenting the antifibrinolytic properties of FXIII. Consequently, this modification should result in enhanced fibroblast migration followed by significantly improved ulcer healing (72-74). Indeed, these suggestions were confirmed by Gemmati et al (72) and Tognazzo et al (73), who found that $34 \mathrm{LL}$ homozygous patients displayed a 2 -fold higher FXIII activity at the same FXIII blood level compared to wild-type $34 \mathrm{VV}$ homozygotous ones. Furthermore, the $34 \mathrm{~L}$ allele was associated with faster reduction of wound size and overall improved wound healing.

$T N F$ receptor $S N P$. Although not studied to date, several SNPs in genes encoding for TNF receptors (TNFRs) may also be considered factors involved in CVU pathophysiology. The competitive role of TNF receptors and their soluble forms (sTNFR1 and sTNFR2) in the pathophysiology of various disorders have already been well documented (84). 
Chae et al found strong associations between the incidence of endometriosis, high serum levels of sTNFR1 and sTNFR2, and genotype, defined as the TNFR2 T676G, A1663G and C1690T SNPs (85). Although these SNPs increase the risk of disease development in endometriosis, it is plausible that, in other conditions, the same polymorphisms may play a beneficial role. One can speculate that, in chronic ulcer pathophysiology, an SNP-associated increased level of soluble TNFR may play a protective role by neutralizing the excess TNF in the wound environment. However, this hypothesis needs to be verified.

FGF-R SNP. Intronic SNPs (rs7895676 and rs2981578) located within intron 2 of the FGF-R2 gene could result in increased expression of the receptor protein, as demonstrated by Meyer et al (86). Moreover, increased activity of the FGF/ FGF-R2 signalling pathway may result from missense mutations around the region encoding for the third Ig-like domain and the tyrosine kinase domain of FGFR-2, which induce the oncogenic FGF autocrine loop and ligand-independent receptor activation, respectively $(87,88)$. Although both of these mutants are defined as risk factors for cancer development, they could nevertheless facilitate rapid wound healing.

\section{Conclusions}

It is difficult to estimate the clinical benefit of SNP screening in determining the genetic risk of CVU development and/or healing. From a pharmacogenomic perspective, in some cases it may aid in the planning of individualized treatment. Clearly, knowledge of the presence of a CVU-promoting mutation/ polymorphism is beneficial to the patient. Since prevention is less burdensome and less expensive than treatment, the detection of a CVU-promoting gene variant should motivate a mutation/polymorphism carrier to introduce prophylaxis early or, if necessary, to begin appropriate treatment for venous insufficiency. If undertaken before a leg ulcer develops, such effective prophylaxis may save a patient from severe health and social problems. In light of this, we believe that genetic screening focussing on the most significant CVU-related SNPs should be considered as elective testing for CVI patients, at least in the CEAP C3/C4 stage.

\section{Acknowledgements}

This study was supported by an individual grant from Warsaw Medical University (1M15/W1/2009).

\section{References}

1. Mekkes JR, Loots MAM, van der Wal AC and Box JD: Causes, investigation and a treatment of leg ulceration. Br J Dermatol 148: 388-401, 2003.

2. Labropoulos N, Manalo D, Patel NP, Tiongson J, Pryor L and Giannoukas AD: Uncommon leg ulcers in the lower extremity. J Vasc Surg 45: 568-573, 2007.

3. Etufugh CN and Phillips TJ: Venous ulcers. Clin Dermatol 25: 121-130, 2007.

4. Ruckley C: Socioeconomic impact of chronic venous insufficiency and leg ulcers. Angiology 46: 67-69, 1997.

5. Jawien A: The influence of environmental factors in chronic venous insufficiency. Angiology 54: S19-S31, 2003.
6. MacKenzie RK, Brown DA, Allan PL, Bradbury AW and Ruckley CV: A comparison of patients who developed venous leg ulceration before and after their 50th birthday. Eur J Vasc Endovasc Surg 26: 176-178, 2003.

7. Milic DJ, Zivic SS, Bogdanovic DC, Karanovic ND and Golubovic ZV: Risk factors related to the failure of venous leg ulcers to heal with compression treatment. J Vasc Surg 49: 1242-1247, 2009.

8. Hehenberger K, Kratz G, Hansson A and Brismar K: Fibroblasts derived from human chronic diabetic wounds have a decreased proliferation rate, which is recovered by the addition of heparin. J Dermatol Sci 16: 144-151, 1998.

9. Pistorius MA: Chronic venous insufficiency: the genetic influence. Angiology 54: S5-S12, 2003.

10. Bradbury AW, MacKenzie RK, Burns $P$ and Fegan $C$ : Thrombophilia and chronic venous ulceration. Eur $\mathbf{J}$ Vasc Endovasc Surg 24: 97-104, 2002.

11. Darvall KA, Sam RC, Adam DJ, Silverman SH, Fegan CD and Bradbury AW: Higher prevalence of thrombophilia in patients with varicose veins and venous ulcers than controls. J Vasc Surg 49: 1235-1241, 2009.

12. Bergan J: Molecular mechanisms in chronic venous insufficiency. Ann Vasc Surg 21: 260-266, 2007.

13. Mustoe TA, O'Shaughnessy K and Kloeters O: Chronic wound pathogenesis and current treatment strategies: a unifying hypothesis. Plast Reconstr Surg 117: S35-S41, 2006.

14. MacKenzie RK, Ludlam CA, Ruckley CV, Allan PL, Burns P and Bradbury AW: The prevalence of thrombophilia in patients with chronic venous leg ulceration. J Vasc Surg 35: 718-722, 2002.

15. Bertina RM, Koeleman BP, Koster T, et al: Mutation in blood coagulation factor $\mathrm{V}$ associated with resistance to activated protein C. Nature 369: 64-67, 1994.

16. Van Boven HH, Reitsma PH, Rosendaal FR, et al: Factor V Leiden (FV R506Q) in families with inherited antithrombin deficiency. Thromb Haemost 75: 417-421, 1996.

17. Maessen-Visch MB, Hamulyak K, Tazelaar DJ, Crombag NH and Neumann HA: The prevalence of factor V Leiden mutation in patients with leg ulcers and venous insufficiency. Arch Dermatol 135: 41-44, 1999.

18. Peus D, von Schmiedeberg S, Pier A, et al: Coagulation factor V gene mutation associated with activated protein $\mathrm{C}$ resistance leading to recurrent thrombosis, leg ulcers and lymphedema: successful treatment with intermittent compression. J Am Acad Dermatol 35: 306-309, 1996.

19. Hackenjos K, Bek M, Schopf E and Vansceidt W: Recurrent ulcerations on both legs since childhood due to a factor $\mathrm{V}$ gene mutation. Dermatology 194: 297-298, 1997.

20. Poort SR, Rosendaal FR, Reitsma PH and Bertina RM: A common genetic variation in the 3'-untranslated region of prothrombin gene is associated with elevated plasma prothrombin levels and an increase in venous thrombosis. Blood 88: 3698-3703, 1996.

21. Brown K, Luddington R, Williamson D, Baker P and Baglin T: Risk of venous thromboembolism associated with a $G$ to $A$ transition at position 20210 in the 3'-untranslated region of the prothrombin gene. Br J Haematol 98: 907-909, 1997.

22. Cumming AM, Keeney S, Salden A, Bhavnani M, Shwe KH and Hay CRM: The prothrombin gene G20210A variant: prevalence in a UK anticoagulant clinic population. $\mathrm{Br} \mathrm{J}$ Haematol 98: 353-355, 1997.

23. Hillarp A, Zöller B, Svensson PJ and Dahlbäck B: The 20210 allele of the prothrombin gene is a common risk factor among Swedish outpatients with verified deep venous thrombosis. Thromb Haemost 78: 990-992, 1997.

24. Kapur RK, Mills LA, Spitzer SG and Hultin MB: A prothrombin gene mutation is significantly associated with venous thrombosis. Arterioscler Thromb Vasc Biol 17: 2875-2879, 1997.

25. Herrmann W: The importance of hyperhomocysteinaemia as a risk factor for disease: an overview. Clin Chem Lab Med 39: 666-674, 2001.

26. Den Heijer M, Rosendaal FR, Blom HJ, Gerrits WBJ and Bos GMJ: Hyperhomocysteinaemia and venous thrombosis: a meta-analysis. Thromb Haemost 80: 874-877, 1998.

27. Ray JG: Meta-analysis of hyperhomocysteinaemia as a risk factor for venous thromboembolic disease. Arch Int Med 158: 2101-2106, 1998.

28. Sharp L and Little J: Polymorphisms in genes involved in folate metabolism and colorectal neoplasia: a HuGE review. Am J Epidemiol 159: 423-443, 2004. 
29. Sam RC, Burns PJ, Hobbs SD, et al: The prevalence of hyperhomocysteinaemia, methylene-tetrahydrofolate reductase C677T mutation and vitamin B12 and folate deficiency in patients with chronic venous insufficiency. J Vasc Surg 38: 904-908, 2003.

30. Cattaneo M, Tsai M, Bucciarelli P, et al: A common mutation in the methylenetetrahydrofolate reductase gene (C677T) increases the risk for deep-vein thrombosis in patients with mutant factor $\mathrm{V}$ (FactorV:Q506). Arterioscler Thromb Vasc Biol 17: 1662-1666, 1997.

31. Eichinger S: Are B vitamins a risk factor for venous thromboembolism? Yes. J Thromb Haemost 4: 307-308, 2006.

32. Bauer KA, Rosendaal FR and Heit JA: Hypercoagulability: too many tests, too much conflicting data. Hematology Am Soc Hematol Educ Program 353-368, 2002.

33. Key NS and McGlennen RC: Hyperhomocyst(e)inemia and thrombophilia. Arch Pathol Lab Med 126: 1367-1375, 2002.

34. Meissner MH, Eklof B, Smith PC, et al: Secondary chronic venous disorders. J Vasc Surg 46: S68-S83, 2007.

35. Yager DR, Kulina RA and Gilman LA: Wound fluids: a window into the wound environment? Int J Low Extrem Wounds 6: 262-272, 2007

36. Baker EA and Leaper DJ: Proteinases, their inhibitors and cytokine profiles in acute wound fluid. Wound Rep Reg 8: 392-398, 2000.

37. Vaalamo M, Weckroth M, Puolakkainen P, et al: Patterns of matrix metalloproteinase and TIMP-1 expression in chronic and normally healing human cutaneous wounds. Br J Dermatol 135: $52-59,1996$.

38. Trengove NJ, Stacey MC, MacAuley S, et al: Analysis of the acute and chronic wound environments: the role of proteases and their inhibitors. Wound Rep Reg 7: 442-452, 1999.

39. Wysocki AB, Staiano-Coico L and Grinell F: Wound fluid from chronic leg ulcers contains elevated levels of metalloproteinases MMP-2 and MMP-9. J Invest Dermatol 101: 64-68, 1993.

40. Wallace HJ, Vandongen YK and Stacey MC: Tumor necrosis factor alpha gene polymorphism associated with increased susceptibility to venous leg ulceration. J Invest Dermatol 126 923-926, 2006

41. Hajeer AH and Hutchinson IV: Influence of TNFalpha gene polymorphisms on TNFalpha production and disease. Hum Immunol 62: 1191-1199, 2001.

42. Hoffsted J, Eriksson P, Hellstrom L, Rossner S, Ryden M and Arner P: Excessive fat accumulation is associated with the TNF-alpha -308 G/A promoter polymorphism in women but not in men. Diabetologia 43: 1085-1088, 2000.

43. Brand E, Schorr U, Kunz I, et al: Tumor necrosis factor-alpha -308 G/A polymorphism in obese Caucasians. Int J Obes Relat Metab Disord 25: 581-585, 2001.

44. Nagy N, Szolnoky G, Szabad G, et al: Tumor necrosis factor$\alpha-308$ polymorphism and leg ulceration - possible association with obesity. J Invest Dermatol 127: 1768-1769, 2007.

45. Beenken A and Mohammadi M: The FGF family: biology, pathophysiology and therapy. Nat Rev Drug Discov 8: 235-253, 2009.

46. Nagy N, Szolnoky G, Szabad G, et al: Single nucleotide polymorphisms of the fibroblast growth factor receptor 2 gene in patients with chronic venous insufficiency with leg ulcer. J Invest Dermatol 124: 1085-1088, 2005.

47. Kawase T, Matsuo K, Suzuki T, et al: FGFR2 intronic polymorphisms interact with reproductive risk factors of breast cancer: results of a case control study in Japan. Int J Cancer 125 1946-1952, 2009.

48. Raskin L, Pinchev M, Arad C, et al: FGFR2 is a breast cancer susceptibility gene in Jewish and Arab Israeli populations. Cancer Epidemiol Biomarkers Prev 17: 1060-1065, 2008.

49. Katoh M: Cancer genomics and genetics of FGFR2. Int J Oncol 33: 233-237, 2008

50. Finch PW and Rubin JS: Keratinocyte growth factor/fibroblast growth factor-7, a homeostatic factor with therapeutic potential for epithelial protection and repair. Adv Cancer Res 91: 69-136, 2004

51. Ashworth JJ, Smyth JV, Pendleton N, et al: The dinucleotide (CA) repeat polymorphism of estrogen receptor beta but not the dinucleotide (TA) repeat polymorphism of estrogen receptor alpha is associated with venous ulceration. J Steroid Biochem Mol Biol 97: 266-270, 2005.

52. Ashworth JJ, Smyth JV, Pendleton N, et al: Polymorphisms spanning the $\mathrm{ON}$ exon and promoter of the estrogen receptorbeta $(E R \beta)$ gene ESR2 are associated with venous ulceration. Clin Genet 73: 55-61, 2008.

53. Brincat M: Hormone replacement therapy and the skin. Maturitas 35: $107-117,2000$
54. Margolis DJ, Knauss J and Bilker W: Hormone replacement therapy and prevention of pressure ulcers and venous leg ulcers. Lancet 359: 675-677, 2002.

55. Ashcroft GS, Greenwell-Wild T, Horan MA, Wahl SM and Ferguson MW: Topical estrogen accelerates cutaneous wound healing in aged humans associated with an altered inflammatory response. Am J Pathol 155: 1137-1146, 1999.

56. Distante S: Genetic predisposition to iron overload: prevalence and phenotypic expression of hemochromatosis-associated HFE-C282Y gene mutation. Scand J Clin Lab Invest 66: 83-100, 2006.

57. Hanson EH, Imperatore $\mathrm{G}$ and Burke W: HFE gene and hereditary hemochromatosis: a HuGE review. Human Genome Epidemiology. Am J Epidemiol 154: 193-206, 2001.

58. Beutler E: The HFE Cys282Tyr mutation as a necessary but not sufficient cause of clinical hereditary hemochromatosis. Blood 101: 3347-3350, 2003

59. Beutler E, Felitti VJ, Koziol JA, Ho NJ and Gelbart T: Penetrance of $\mathrm{C} 282 \mathrm{Y}$ hereditary haemochromatosis mutation in USA. Lancet 359: 211-218, 2002.

60. McCune CA, Ravine D, Worwood M, Jackson HA, Evans HM and Hutton D: Screening for hereditary haemochromatosis within families and beyond. Lancet 362: 897-898, 2003.

61. Zamboni P and Gemmati D: Clinical implications of gene polymorphisms in venous leg ulcer: a model in tissue injury and reparative process. Thromb Haemost 98: 131-137, 2007.

62. LeVine SM and Chakrabarty A: The role of iron in the pathogenesis of experimental allergic encephalomyelitis and multiple sclerosis. Ann NY Acad Sci 1012: 252-266, 2004.

63. Zamboni P, Izzo M, Tagnazzo S, et al: The overlapping of local iron overload and HFE mutation in venous leg ulcer pathogenesis. Free Radic Biol Med 40: 1869-1873, 2006.

64. Zamboni P, Tognazzo S, Izzo M, et al: Hemochromatosis C282Y gene mutation increases the risk of venous leg ulceration. J Vasc Surg 42: 309-314, 2005.

65. Bao P, Kodra A, Tomic-Canic M, Golinko MS, Ehrlich HP and Brem H: The role of vascular endothelial growth factor in wound healing. J Surg Res 153: 347-358, 2009.

66. Carmeliet P and Jain RK: Angiogenesis in cancer and other diseases. Nature 407: 249-257, 2000

67. Kim YS, Park SW, Kim MH, et al: Novel single nucleotide polymorphism of the VEGF gene as a risk predictor for gastroduodenal ulcers. Gastoenterology 23: S131-S139, 2008.

68. Hsiao PJ, Lu MY, Chiang FY, Shin SJ, Tai YD and Juo SHH: Vascular endothelial growth factor gene polymorphisms in thyroid cancer. J Endocrinol 195: 265-270, 2007.

69. Cosín R, Gilabert-Estellés J, Ramón LA, et al: Vascular endothelial growth factor polymorphisms $(-460 \mathrm{C} / \mathrm{T},+405 \mathrm{G} / \mathrm{C}$ and 936C/T) and endometriosis: their influence on vascular endothelial growth factor expression. Fertil Steril 92: 1214-1220, 2009.

70. Renner W, Kotschan C, Hoffmann C, Obermayer-Pietsch B and Pilger E: A common $936 \mathrm{C} / \mathrm{T}$ mutation in the gene for vascular endothelial growth factor is associated with vascular endothelial growth factor plasma levels. J Vasc Res 37: 443-448, 2000.

71. Rogers MS and D'Amato RJ: The effect of genetic diversity on angiogenesis. Exp Cell Res 312: 561-574, 2006.

72. Gemmati D, Tognazzo S, Serino ML, et al: Factor XIII V34L polymorphism modulates the risk of chronic venous ulcer progression and extension. Wound Repair Regen 12: 512-517, 2004.

73. Tognazzo S, Gemmati D, Palazzo A, et al: Prognostic role of factor XIII gene variants in nonhealing venous leg ulcers. J Vasc Surg 44: 815-819, 2006.

74. Gemmati D, Tognazzo S, Catozzi L, et al: Influence of gene polymorphisms in ulcer healing process after superficial venous surgery. J Vasc Surg 44: 554-562, 2006.

75. Shen LL, Hermans J, McDonagh J, McDonagh RP and Carr M: Effects of calcium ion and covalent crosslinking on formation of elasticity of fibrin gels. Thromb Res 6: 255-265, 1975.

76. Bakker EN, Pistea A and VanBavel E: Transglutaminases in vascular biology: relevance for vascular remodeling and atherosclerosis. J Vasc Res 45: 271-278, 2008.

77. Ueyama M and Urayama T: The role of factor XIII in fibroblast proliferation. Jpn J Exp Med 48: 135-142, 1978.

78. Zamboni P, DeMattei M, Ongaro A, et al: Factor XIII contrasts the effects of metalloproteinases in human dermal fibroblast cultured cells. Vasc Endovasc Surg 38: 431-438, 2004.

79. Inbal A, Lubetsky A, Krapp T, Castel D, Shaish A and Dickneitte G: Impaired wound healing in factor XIII deficient mice. Thromb Haemost 94: 432-437, 2005. 
80. Hildenbrand T, Idzko M, Panther E, Norgauer J and Herouy Y: Treatment of nonhealing leg ulcers with fibrin-stabilizing factor XIII: a case report. Dermatol Surg 28: 1098-1099, 2002.

81. Gallivan L, Markham AF and Anwar R: The Leu564 factor XIII variant results in significantly lower plasma factor XIII levels than the Pro564 variant. Thromb Haemost 82: 1368-1370, 1999.

82. Yee VC, Pedersen LC, Le Trong I, Bishop PD, Stenkamp RE and Teller DC: Three-dimensional structure of transglutaminase: human blood coagulation factor XIII. Proc Natl Acad Sci USA 91: 7296-7300, 1994.

83. Kohler HP, Ariens RA, Whitaker P and Grant PJ: A common coding polymorphism in the FXIIIA-subunit gene (FXIII Val34Leu) affects cross-linking activity. Thromb Haemost 80: 704, 1998.

84. Aderka D: The potential biological and clinical significance of the soluble tumor necrosis factor receptors. Cytokine Growth Factor Rev 7: 231-240, 1996.
85. Chae SJ, Kim H, Jee BC, Suh CS, Kim SH and Kim JG: Tumor necrosis factor (TNF)-TNF receptor gene polymorphisms and their serum levels in Korean women with endometriosis. Am J Reprod Immunol 60: 432-439, 2008.

86. Meyer KB, Maia AT, O'Reilly M, et al: Allele-specific up-regulation of FGFR2 increases susceptibility to breast cancer. PLoS Biol 6: e108, 2008.

87. Jang JH, Shin KH and Park JG: Mutations in FGFR2 genes associated with human gastric and colorectal cancers. Cancer Res 61: 3541-3543, 2001.

88. Pollock PM, Gartside MG, Dejeza LC, et al: Frequent activating FGFR2 mutations in endometrial carcinomas parallel germline mutations associated with craniosynostosis and skeletal dysplasia syndromes. Oncogene 26: 7158-7162, 2007. 